See discussions, stats, and author profiles for this publication at: https://www.researchgate.net/publication/325011324

\title{
Effect of arbuscular mycorrhizal fungi and poultry manure on growth and nutrients contents of maize in different soil type
}

Article in JOURNAL OF ADVANCES IN AGRICULTURE · May 2018

Dol: $10.24297 /$ jaa.v4i2.4274

\section{CITATION}

3 authors, including:

Rakiya Abdullahi

University of Maiduguri

10 PUBLICATIONS 52 CITATIONS

SEE PROFILE
READS

355

Samuel Lihan

University Malaysia Sarawak

74 PUBLICATIONS 446 CITATIONS

SEE PROFILE

Some of the authors of this publication are also working on these related projects:

Burkhoderia pseudomallei View project

Isolation of indigenous arbuscular mycorrhizal fungi and selection of host plant for inoculum production View project 


\title{
Effect of arbuscular mycorrhizal fungi and poultry manure on growth and nutrients contents of maize in different soil type
}

\begin{abstract}
Abdullahi, $\mathrm{R}^{1}$., Lihan, $\mathrm{S}^{1}$., Edward $\mathrm{R}^{2}$ and Demie, L. $\mathrm{S}^{1}$.
${ }^{1}$ Department of Molecular Biology, Universiti Malaysia Sarawak,Kota Samarahan, Sarawak, Malaysia.

${ }^{2}$ Department of Plant Science and Environmental Ecology, Universiti Malaysia Sarawak, Kota Samarahan,

Sarawak, Malaysia

rakiyaa6@gmail.com;Isamuel@frst.unimas.my;erebicca@gmail.com;suzellademie@gmail.c

\section{ABSTRACTS}

om

Public concerned about food safety and quality have raised interest in manipulating soil nutrients management strategies that could reduce potential threat on environment and sustain food production. Recently, the application of arbuscular mycorrhizal fungi (AMF)as bio-fertilizer has gained recognition especially, in low-input agriculture. The fungi are known to improve plant nutrition and growth. However, this effect may differ according to soil properties and nutrients concentration. A greenhouse experiment was conducted to investigate the effect of AMF and poultry manure (PM) on growth and nutrients contents in maize compared to chemical fertilizer; and to determine the effect of soil properties on colonization potential of AMF. The experiment consists of 13 treatments combinations in 2 soil types (loam and peat), viz; 6 application rates of composted PM in tones (t) ha ${ }^{-1}(0,4,6,8,10$ and 12) and 2 levels of AMF; inoculated (+AMF) and un-inoculated (AMF) plus recommended dose of NPK (RD NPK). Un-inoculated plants showed no symptoms of root colonization and recorded no AMF spore under both soils. Addition of PM stimulated AMF colonization and sporulation, the highest root colonization $(R C \%)$ and spore counts were recorded at $8 \mathrm{t} P M+A M F$ under loam and $12 \mathrm{t} P M+A M F$ in peat soils. Shoot dry biomass at 8 and 12 t PM+AMF under loam and peat were comparable to RD NPK. Applying 8 and 12 t PM+AMF in loam and peat recorded the highest N\& K comparable to RD NPK. However, $P$ content in shoot were statistically higher at 8,10 \& 12 t PM+AMF in loam and at 12 t PM+AMF in peat compared to RD NPK. Application of $10 \& 12$ t PM+AMF in loam significantly decreased plant growth, lowered AMF RC\%, and nutrient content ( $\mathrm{N} \& \mathrm{~K})$. There was a strong positive correlation between shoot dry biomass and $\mathrm{RC} \%$ in loam $\left(R^{2}=0.740 \mathrm{P}<0.01\right)$ and peat $\left(R^{2}=0.884 \mathrm{P}<0.01\right)$. From the results of this study, it could be concluded that AMF have increased the efficiency use of PM and their integration have the potential to improve plant growth due to enhanced nutrients uptake and stimulated $\mathrm{RC} \%$ in both soils. Results also indicated significantly higher shoot dry biomass, nutrients content $(N, P, \& K)$, spore counts and RC \% in loam soil compared to peat, indicating that soil properties has a significant influence on effectiveness AMF.
\end{abstract}

Keywords: AMF inoculation; poultry manure (PM); nutrients content; NPK fertilizer; maize growth; soil properties.

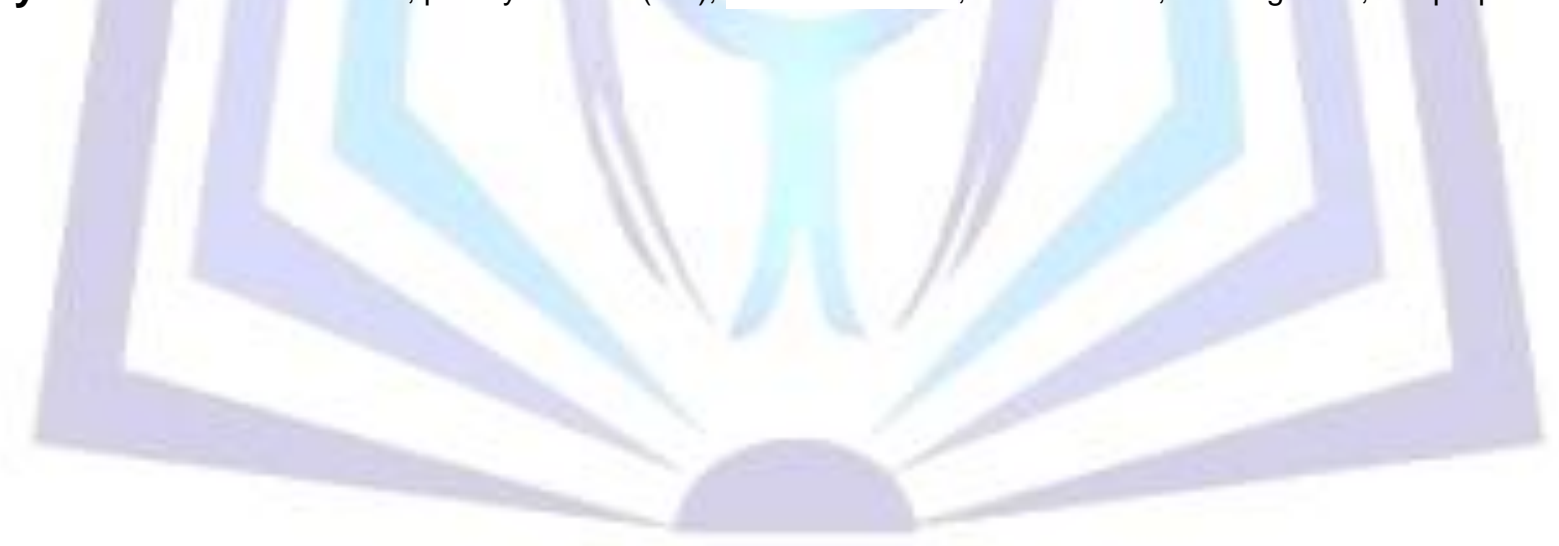

\section{Council for Innovative Research}

Peer Review Research Publishing System

Journal: JOURNAL OF ADVANCES IN AGRICULTURE

Vol 4 , No. 2

www.cirjaa.com, jaaeditor@gmail.com 


\section{INTRODUCTION}

For optimum maize growth and yield, high fertilizer application is essential. Fertilizer sources varied from organic, chemical and bio-fertilizers. Of all the fertilizers, chemical fertilizer is the most accepted and widely used by farmers due to fast and direct effect on plant growth. However, consequences from long term usage have degraded soil from its productive quality thereby reducing yield (Loveland and Webb, 2003; Phelan, 2004; Khan et al., 2008) due to poor soil structure, low soil organic matter content (Fließbach et al., 2007; Ball, 2006; Roldản et al., 2005) and imbalance in soil microbia communities, affecting agro-ecosystem functioning (Griffiths et al., 2001; Gunapala and Scow, 1998). As a result of those negative impacts, huge interest is recently geared towards promoting soil nutrients management techniques that could strengthen sustainable agricultural structure. Application of organic amendments and microbial inoculants (bio-fertilizer) is a good agronomic practice that could maintain fertility status of soil, improve plant nutrients uptake and minimize the use of chemical fertilizer. Applying poultry manure (PM) to agricultural farms has increased recently as best means for its disposal (Erich et al., 2002; McDowell and Sharpley, 2004; Toor et al., 2006). It is the most excellent of all animal manures due to high content of N, P, and K (Ma et al., 2009; Nahm et al., 2003). PM supplies nutrients more readily than other organic source (Garg and Bahla, 2008; Chandrashekara et al., 2000), improves soil fertility (Eriksen, 2005), motivate microbial growth (Suresh et al., 2004), improve soil structure which increases infiltration rate and soil water holding capacity (Deksissa et al., 2008; Belay et al., 2001). Addition of organic amendments to soil enhances microbial community and activities. Important group among the microorganisms are arbuscular mycorrhizal fungi (AMF) which form symbiotic association with majority of higher plants aiding nutrients and water uptake limited for plant growth; in exchange, fungus obtains fixed carbon from plant host. Plants colonized by AMF benefit more from enhanced water and nutrients uptake, especially, N, P, Cu, and Zn. Thus, improve plant growth and yield, ensured plant health (Lingua et al., 2002; Pozo et al., 2002) and resistance to environmental stress (Auge, 2001; Koske and Gemma, 2005) compared to un-colonize plants.

PM and AMF could serve as sustainable nutrient alternative to chemical fertilizer. This is due to the potential of the fungi to utilize unavailable organic nutrients and increase the efficiency use of nutrientsthrough enhanced nutrients uptake (Mamatha et al., 2002; Atimanav and Adholeya, 2002; Joner, 2000), which might improve plant growth and yield (Jackson et al., 2002; Martin and Stutz, 2004; Ortas et al., 2011). Earlier workers have clearly revealed the positive effect of organic amendments in combination with AMF (Caravaca et al., 2003; Douds et al., 2010; Tanwar et al., 2013) on plant growth and improve nutrients uptake. However, excessive application of poultry manure might be undesirable due to risk of soil and water pollution (Sharpley et al., 1999; Herpperly et al., 2009) and most particularly, the high content of $P$ in the manure could affect AMF colonization potential (Jordan et al., 2000; Varga et al., 2004). In this context, it could be interesting to understand the optimum application rate of PM that could enhance maximum benefits from AMF symbiosis. The aim of this research is to determine the optimum application rate of PM that could stimulate AMF-plant symbiosis and provide nutrients for optimum growth of maize compared to chemical fertilizer and to investigate the effect of soil properties on colonization potential of AMF.

\section{MATERIALS AND METHODS}

Experimental site:The experiment was conducted at the Forestry Research Garden green house (East Campus), University Malaysia Sarawak, Kota Samarahan. Located at $0^{\circ} 50^{\prime}$ and $5^{\circ} \mathrm{N}$ and $109^{\circ} 36^{\prime}$ and $115^{\circ} 40^{\prime} \mathrm{E}$, having average rainfall of 247 days per annum with annual mean precipitation between 2,500 and 5,000, and a monthly minimum rainfall recorded around June or July but exceeded $100 \mathrm{~mm}$ (Andriesse, 1968). The temperatures ranges between $23^{\circ} \mathrm{C}\left(73^{\circ} \mathrm{F}\right)$ and $33^{\circ} \mathrm{C}\left(91^{\circ} \mathrm{F}\right)$ in the early hours of the morning and during mid-afternoon respectively with heat index reaching $42{ }^{\circ} \mathrm{C}$ $\left(108^{\circ} \mathrm{F}\right)$ during dry season due to humidity reaching to about $85 \%$.

AMF inoculum: AM inoculum was a mixture of Gl. mossea, Gl. geosporum and Gl. etunicatum from trap cultures of Cymbopogon citratus, containing spores, soil with infected root fragments and hyphae.

Source of poultry manure:Composted poultry manure was procured from a commercial poultry farm around Kota Samarahan. Prior to use, the nitrogen, phosphorus and potassium composition of manure were analyzed using Kjeldahl method (A.O.A.C, 1970) and tri-acid mixture for phosphorus and potassium as outlined by Jackson, (1973). Chemical analysis of the manure indicated a $\mathrm{pH}$ of $8.3 ; \mathrm{N}, 2.3 \% ; \mathrm{P}, 1.3 \%$ and $\mathrm{K}, 1.6 \%$.

Treatments and experimental design:The experiments consist of 6 levels of poultry manure in tones $(t)$ ha ${ }^{-1}(0,4$, $6,8,10, \& 12) \times 2$ levels of AM fungi, inoculated (+AMF) and un-inoculated (-AMF) +1 recommended dose of NPK (RD NPK) chemical fertilizer making 13 treatment combinations $\times 2$ (soil types) laid out in a completely randomized block design (CRBD). The following scheme was used for categorizing the treatment combinations;Un-inoculated (-AMF): $0 \mathrm{t}$ PM-AMF (Control), 4 t PM-AMF, 6 t PM-AMF, 8 t PM-AMF, 10 t PM-AMF, 12 t PM-AMF; Inoculated (+AMF): $0 \mathrm{t}$ $\mathrm{PM}+\mathrm{AMF}$ (AMF+ only), $4 \mathrm{t} \mathrm{PM}+\mathrm{AMF}, 6 \mathrm{t} \mathrm{PM}+\mathrm{AMF}$, 8 t PM+AMF , 10 t PM+AMF, 12 t PM+AMF and RD NPK.

Collection of soil samples and preparation of pots:Composite soil samples at $0-15 \mathrm{~cm}$ depth of loam and peat soils were sampled from farms around Universiti Malaysia Sarawak. Prior to experiment, the physical and chemical properties of soils were determined using standard methods. Characteristics of soil are presented in table 1. Soil samples were passed through $4.0 \mathrm{~mm}$ sieve and steam sterilized at $121^{\circ} \mathrm{C}$ for $2 \mathrm{~h}$ to kill all indigenous microorganisms including AM fungi. Three kilogram $(3 \mathrm{~kg}$ ) of each soil was weighed into individual plastic pot of $15 \mathrm{~cm}$ (diameter) $\mathrm{x} 20 \mathrm{~cm}$ (height) capacity. Soils were mixed thoroughly with poultry manure according to treatments a week before sowing. Inoculated pots received $10 \mathrm{~g} \mathrm{pot}^{-1}$ of AM inoculum placed $3 \mathrm{~cm}$ below pot surface and $10 \mathrm{~g} \mathrm{pot}^{-1}$ of sterilized soil for un-inoculated pots. RD NPK at $130 \mathrm{~kg} \mathrm{~N}, 130 \mathrm{~kg} \mathrm{P}$, and $67 \mathrm{~kg} \mathrm{~K}$ (Department of Agriculture, 2003) was applied to appropriate pots in form of 